\title{
Open surgical procedures for incisional hernias
}

Dennis den Hartog ${ }^{2}$, Alphons HM Dur ${ }^{3}$, Wim E Tuinebreijer ${ }^{1}$, Robert W Kreis ${ }^{3}$

${ }^{1}$ Wijk aan Zee, Netherlands.

${ }^{2}$ Surgery, Erasmus MC, University Medical Center Rotterdam, Rotterdam, Netherlands.

${ }^{3}$ Surgery, Red Cross Hospital, Beverwijk, Netherlands

Contact address: Wim E Tuinebreijer, Relweg 59, Wijk aan Zee, 1949 EC, Netherlands. wetuineb@knmg.nl 


\section{ABSTRACT}

\section{Background}

Incisional hernias occur frequently after abdominal surgery and can cause serious complications. The choice of a type of open operative repair is controversial. Determining the type of open operative repair is controversial, as the recurrence rate may be as high as $54 \%$.

\section{Objectives}

To identify the best available open operative techniques for incisional hernias.

\section{Search strategy}

Electronic databases MEDLINE, EMBASE, LILACS, and the Cochrane Central Register of Controlled Trials (CENTRAL) were searched from 1990 to 2007 and trials were identified from the known trial reference lists.

\section{Selection criteria}

Studies were eligible for inclusion if they were randomized trials comparing different techniques for open operative techniques for incisional hernias.

\section{Data collection \& analysis}

Statistical analyses were performed using the fixed effects model. Results were expressed as relative risk for dichotomous outcomes and weighted mean difference for continuous outcomes with $95 \%$ confidence intervals. 


\section{Main results}

Eight trials comparing different open repairs for incisional hernias were identified; one trial was excluded. The included studies enrolled 1,141 patients. The results of three trials comparing suture repair versus mesh repair were pooled. Hernia recurrence was more frequent, wound infection less frequent in the direct suture group compared to the onlay or sublay mesh groups. The recurrence rates of two trials comparing onlay and sublay positions were pooled. This comparison yielded no difference in recurrences (two studies pooled), although operation time was shorter in the onlay group (one study). No difference was found in recurrence, satisfaction with cosmetics, or infection between the onlay standard mesh and skin autograft groups, following analysis pooling the two treatment arms. However, the analysis demonstrated less pain in the skin autograft group. Other trials comparing different mesh materials or different positions of the mesh, or comparing mesh with the components separation technique are described individually. The comparison between lightweight and standard mesh showed a trend for more recurrences in the lightweight group. The comparison between onlay and intraperitoneal mesh positions resulted in non significant fewer hernia recurrences, less seroma formation and more postoperative pain in the intraperitoneal group. No differences in the recurrence rates between the components separation and the intraperitoneal mesh technique.

\section{Authors' conclusions}

There is good evidence from three trials that open mesh repair is superior to suture repair in terms of recurrences, but inferior when considering wound infection. Six trials yielded insufficient evidence as to which type of mesh or which mesh position (on- or sublay) should be used. There was also insufficient evidence to advocate the use of the components separation technique. 


\section{PLAIN LANGUAGE SUMMARY}

Open surgical procedures for incisional hernias.

An incisional hernia is a bulge of tissue or an organ through an operation scar in the abdominal wall. Incisional hernias occur in 10 to 23 percent after abdominal operations. This review question the choice of open operative repair technique, somehow controversial due to a high failure rate, reported as high as 54\%. Open mesh repair has a lower failure rate (recurrence) than open suture repair, but mesh repair are complicated by more wound infections. No conclusions could be drawn on which type of mesh should be used because of lack of trials. Also no inference was drawn about the position of the mesh (below or above the fascia). More randomized clinical trials are needed to answer all the remaining questions. 


\section{BACKGROUND}

Incisional hernias are ventral hernias through an operation scar and are a serious complication of abdominal surgery. Incisional hernias occur in 11 to 23 percent of laparotomies (Cassar 2005). Incisional hernias enlarge over time and can result in serious complications such as pain, bowel obstruction, incarceration and strangulation, and enterocutaneous fistula.

Furthermore, the quality of life and chances for employment are reduced in patients suffering from incisional hernias.

The repair of such hernias can be performed through either an open or laparoscopic technique (Korenkov 2001). The open technique may be a simple hernioplasty (Mayo duplication or fascia-adaptation), a components separation, or a mesh repair. The components separation technique is based on enlargement of the abdominal wall surface by separation and advancement of the muscular layers. The mesh can be placed using onlay (prefascial), sublay (subfascial or preperitoneal) or inlay techniques. In an inlay repair, the fascia is not approximated but the gap is closed by the mesh. The mesh consists of either autoplastic or alloplastic material. In an autoplastic graft, a cutis flap is used (skin autograft hernioplasty). Synthetic mesh can be further classified into three types (Amid 1997). Type I mesh is a totally macroporous prosthesis consisting of monofilament or double filament polypropylene. Type II mesh is a completely microporous prosthesis, such as expanded PTFE. Type III mesh is a mixed-prosthesis consisting of a macroporous prosthesis with multifilamentous or microporous components, such as PTFE mesh.

The recurrence rate following open suture repair may be as high as 54\% (Paul 1998) and as high as 32\% for open mesh repair (Burger 2004). Recurrence rates for laparoscopic repair appear to be comparable to the open mesh procedure, but require a shorter hospital stay (Cassar 2005). In a Swedish cost analysis study (including sick leave), the costs for incisional 
hernia repair were 6,122 Euro and 5,458 Euro for suture and mesh repairs, respectively (Israelsson 2003). The quality of life, as assessed by physical function scores obtained through a questionnaire (SF 36), improved four months after mesh repair (Conze 2005). Several conditions are associated with the development of incisional hernia: suture technique, wound infection, increased abdominal wall tension and metabolic connective tissue disorder, specifically, abdominal aortic aneurysms (Klinge 2000; Klinge 2001). A Cochrane Review found no difference in the risk of incisional hernia comparing midline with transverse incisions (Brown 2005).

Although incisional hernias result from a process that initiates within weeks of surgery, clinical appearance may take years (Burger 2005; Pollock 1989).

\section{OBJECTIVES}

The primary objective of this review was to identify the best available open operative techniques for repairing incisional hernias.

\section{METHODS}

\section{Criteria for considering studies for this review}

\section{Types of studies}

We included only randomized controlled studies that compared different open techniques for closure of incisional hernias. All included studies reported at least a half year follow-up, and 
at least 70 percent of the study participants had a mean follow-up of one year. We did not restrict the type of incision (midline, transverse, paramedian, lumbar, etc.) used in the trials.

\section{Types of participants}

We included trials that compared the interventions of interest in adult patients of both genders. Mixed studies that also included patients with other types of hernias (e.g., primary epigastric, umbilical, parastomal) were excluded. Patients with elective and emergency care were also included.

\section{Types of interventions}

Included trials compared the open primary closure technique procedure with either another technique or the same open primary closure technique with a prosthesis. We also included trials that compared different prosthetic materials. No studies investigating laparoscopic techniques were included.

We included trials that compared any of the following interventions separately or in combination:

Open suture repairs as simple adaptation of fascia, duplication of fascia (Mayo procedure) and components separation.

Open mesh repairs with allo- and autoplastic materials.

\section{Types of outcome measures}

The primary outcome for the review was the number of participants who developed a recurrent incisional hernia as defined in the included studies. We reported the primary outcome at different follow-up times, as available from the individual studies, although the 
primary outcome of interest was the rate of recurrence of incisional hernia after at least a oneyear follow-up.

The secondary outcomes for the review were defined by the individual investigators and were as follows:

Length of hospital stay in days, enterocutaneous fistula, cosmesis, patient satisfaction, operating time (minutes) and wound pain. Acute postsurgical pain due to the incision was distinguished from chronic pain (possibly due to mesh reaction). Wound complications including acute infections, and chronic infections such as sinus/fistula tracts, mesh infection, and seroma/haematoma formation were also secondary outcomes.

\section{Search methods for identification of studies}

See: Colorectal Cancer Group methods used in reviews.

Electronic search included MEDLINE, EMBASE, LILACS, and the Cochrane Central Register of Controlled Trials (CENTRAL). There was no limitation based on language or date of publication.

Manual searches including reference lists of all included studies were used to identify randomized trials that the electronic search may have failed to identify.

We used the following search terms in different combinations as MeSH (Medical Subject Heading) terms and as text words: incisional hernia, ventral hernia, and surgical treatment outcome. 


\section{Data collection and analysis}

\section{Selection of studies}

Two reviewers independently assessed the title and abstracts of all reports identified by electronic and manual searches. Each report was labeled as (a) definitely exclude, (b) unsure or (c) definitely include. Full text articles of abstracts labeled as "unsure" were reassessed according to the inclusion criteria for this review. Any differences were resolved through discussion. Studies labeled as "definitely exclude" were excluded from the review, while studies labeled as "definitely include" were further assessed for methodological quality. Abstract publications were only selected when a full manuscript was obtained from the study authors.

\section{Data extraction and management}

Two reviewers independently extracted the data for the primary and secondary outcomes and entered the data into paper data collection forms developed for this purpose. Discrepancies were resolved by discussion. Authors of included studies were contacted for missing data. One reviewer entered all data into RevMan 4.2. The second reviewer independently reentered the data, using the double data-entry facility in order to verify the data entered

\section{Assessment of methodological quality of included studies}

Two reviewers independently assessed the included studies for sources of systematic bias in trials, according to the guidelines in section 6 of the Cochrane Handbook for Systematic Reviews of Interventions 4.2.5 (Higgins 2005). The studies were evaluated for the following criteria: allocation concealment (selection bias), rates of follow-up and intention to treat analysis (attrition bias). Allocation concealment was graded as (a) adequate, (b) inadequate or 
(c) unsure. Authors of studies labeled "unsure" were contacted for further clarification.

Differences between the two reviewers were resolved by discussion. Masking of outcome assessors in the included studies was assessed.

\section{Measures of treatment effect}

Data analysis followed the guidelines outlined in Section 8 of the Cochrane Handbook for Systematic Reviews of Interventions 4.2.5 (Deeks 2005).

Dichotomous outcomes:

Dichotomous outcomes (e.g., presence/absence of recurrence, complications) were reported as proportions and were directly compared (difference in proportions). We used these proportions to calculate risk ratios (RRs) and absolute risk reductions (risk differences) with 95\% confidence intervals (CIs). Data from survival curves comparing different treatments were extracted to calculate hazard ratios (Parmar 1998).

\section{Continuous outcomes:}

For continuous data (e.g., operating time, length of hospital stay, quality of life, pain scores) results are presented as weighted mean differences (WMD).

We used Review Manager 4.2 software (RevMan 4.2, Cochrane software) for generating the figures and statistical analyses.

\section{Assessment of heterogeneity}

We explored heterogeneity using the chi-squared test with significance set at a p-value less than 0.10 . The quantity of heterogeneity was estimated by the I-squared statistic. Because prior statistical evidence existed for homogeneity of effect sizes, the planned analysis used a fixed effect model. 


\section{Sensitivity analysis}

Sensitivity analyses were conducted to determine the impact of exclusion of studies with lower methodological quality. The sensitivity analysis was performed for the recurrence rate in order to test the effect of removing studies. The methodological quality of studies was inadequate in the following situations: when the allocation sequence was not generated by a computer or random number table, when the reasons for dropouts and withdrawals were not described, or when the analysis was not performed on intention to treat basis.

\section{RESULTS}

\section{Description of studies}

A total of seven trials comparing different open surgical procedures for incisional hernias were included (see 'Characteristics of included studies' table for further details) with a total enrolment of 1,141 patients. In addition, one study with 65 patients was excluded (see 'Characteristics of excluded studies') because follow-up in one of the groups was limited to only four months (Schumpelick 1999). From all studies a full publication from a journal or a copy of the original poster was retrieved (Baracs 2007; Köhler 2004).

\section{Risk of bias in included studies}

Results of the quality assessment are given in the 'Characteristics of included studies' table. In general, the study quality was assessed as fair to moderate with regard to methodology and all trials were large enough to detect useful clinical differences between groups. 


\section{Randomization}

Allocation concealment was described in four trials (Afifi 2005; Conze 2005; Korenkov 2002a; de Vries 2007a) but was absent in three others (Burger 2004; Köhler 2004; Baracs 2007). Allocation concealment was verified by e-mail correspondence with one of the authors of the study of Köhler. Incomplete information about the randomization procedure was completed by the authors of the Baracs study.

\section{Participants lost to follow up}

All studies, except one (Baracs 2007), reported losses at follow-up. In four studies, the intention-to-treat analysis was explicitly undertaken (Burger 2004; Conze 2005; Korenkov 2002a; de Vries 2007a), while could be concluded from the Köhler 2004 study from the flow diagram. In the Afifi 2005 study, there was no loss of follow-up and the interventions were given following the random allocation. Thus, the intention-to-treat analysis was secure in six of the studies and was unable to be determined only in the Baracs 2007 study.

\section{Blinding}

Five of the studies did not provide enough information to determine the strategies used to blind participants or outcome assessors (Afifi 2005; Burger 2004; de Vries 2007a; Köhler 2004; Baracs 2007). For these studies, the blinding strategy was verified by direct e-mail correspondence with one of the authors. In the Köhler study, blinding was reported not to be possible. In one study, the patients were informed about the operation they received and subsequently notified the assessors, who were thus, unblinded (Korenkov 2002a). The patients and outcome assessors were blinded to the treatment group in the 2005 study by Conze (Conze 2005). In the Baracs 2007 study postoperative monitoring was done by a surgeon who had not operated on the patient. 


\section{Length of follow-up}

The Afifi 2005 study had a follow-up length of 30 months (median), the Baracs 2007 study had a minimum of 3 years and a maximum of 5 years of follow-up, the Burger 2004 study had a median follow-up of 75 months for the suture repair patients and 81 months for the mesh repair group, the Conze 2005 study had a follow-up of 2 years, the de Vries 2007a study had a mean follow-up of 22 months, the Korenkov 2002a study had a mean follow-up of 16 months and the Köhler 2004 study a mean follow-up of 1 year. This last study was included because $70 \%$ of the patients had a minimal follow-up time of one year.

\section{Effects of interventions}

Statistical analyses were performed using the fixed effects model, since we assumed that all variation between studies was caused by chance and that studies measured the same overall effect. Even if a random-effects model was used, our conclusions remained the same. The results were expressed as relative risk (RR) for dichotomous outcomes and weighted mean difference (WMD) for continuous outcomes with 95\% confidence intervals (CI).

Data from three studies comparing suture repair with mesh repair in onlay or sublay position could be pooled (Burger 2004; Korenkov 2002a; Baracs 2007). From two of these studies, hazard ratios for recurrences were calculated and pooled with the Peto odds method (Burger 2004; Korenkov 2002a). The Luijendijk 2000 study is a prior version of the study of Burger 2004. The publication of Weber 2002 is a description of the planned design of the Baracs 2007 study. Data from two studies comparing the sublay versus the onlay position could be pooled for the recurrence rate outcome (Köhler 2004; Baracs 2007), but not for the outcome operation time (standard deviations missing).

Data from the five studies comparing different types of mesh and different positions of these types of mesh could not be pooled due to clinical and methodological heterogeneity, and thus 
are described individually. One study is a double trial and is included as two separate trials (Korenkov 2002a; Korenkov 2002b). Korenkov 2002a is a three-armed trial on simple hernias comparing suture repair, mesh repair and skin autograft. Korenkov 2002b is a two-armed trial on complex hernias comparing mesh repair with skin autograft. Part of the three-armed trial was pooled with the two-armed trial. Hazard ratios for recurrences could also be calculated for the Köhler 2004 and de Vries 2007a studies.

One trial with 65 patients was excluded because follow-up in one of the groups was limited to only four months (Schumpelick 1999).

\section{Suture repair versus mesh repair in the onlay or sublay position}

\section{Recurrence}

Korenkov 2002a, Burger 2004, and Baracs 2007 data were pooled for the analysis of recurrences.

Hernia recurrence was more frequent in the suture repair group than in the mesh group (Comparison 01:01: RR 1.85, 95\% CI 1.33 to 2.56; $\mathrm{p}=0.0002)$. These three studies included small hernias defined as being smaller than $10 \mathrm{~cm}$, smaller than $6 \mathrm{~cm}$ and smaller than 25 cm2, respectively. In contrast with Korenkov 2002a and Burger 2004 , who compared mesh in the onlay position with suture repair, Baracs 2007 compared mesh repair in the sublay position with suture repair. Omitting the Baracs 2007study from the analysis did not change the outcome (sensitivity analysis).

The pooled recurrence rate was 33.3\% for the suture repair group and $16.4 \%$ for the mesh group. The number needed to treat to benefit (NNTb) was 6 for the suture group patients. The calculated hazard ratio for recurrences in the Burger 2004 study was 2.08 (CI 1.35 to 3.22) and it was 1.36 (CI 0.31 to 6.03) for the Korenkov 2002a study. Pooling of these two studies yielded a hazard ratio of 2.01 (CI 1.32 to 3.06; $\mathrm{p}=0.001$ ). 
Korenkov 2002a and Burger 2004 data were pooled for the following analysis.

\section{Chronic wound pain}

The frequency of chronic wound pain was not statistically different between the groups (Comparison 01:02: RR 1.02, 95\% CI 0.62 to 1.68; $\mathrm{p}=0.92$ ). The pain outcome in the Korenkov 2002a study was defined as the presence of wound pain measured on a visual analogue scale (VAS) after one year, therefore corresponding to a VAS score greater than one. However in the Burger 2004 study chronic wound pain was scored positively when the patient had experienced scar pain during the last month prior to follow-up (median follow-up for suture repair was 75 months and 81 months for mesh repair patients). Satisfied with cosmetic result The satisfaction with the cosmetic result was not statistically different between the groups (Comparison 01:03: RR 0.90, 95\% CI 0.68 to 1.20; $\mathrm{p}=0.48$ ).

\section{Wound Infection}

Wound infection was more frequent in the mesh group than in the suture repair group (Comparison 01:04: RR 0.09, 95\% CI 0.01 to 0.70; p=0.02). In the Burger 2004 study, 6 of the 60 mesh repair patients were scored as having deep infection: 3 patients had a fistula from mesh to skin, 1 patient a mesh infection and 2 patients an enterocutaneous fistula. In the Korenkov 2002a study, 4 of the 39 mesh repair patients were scored as having local infectious complications. Two meshes had to be removed.

The pooled infection rate was $0 \%$ for the suture repair group and $10.1 \%$ for the mesh group. The number needed to treat to harm (NNTh) was 10 for the mesh group patients.

\section{Lightweight mesh versus standard mesh in sublay position}

The Conze 2005 study investigated lightweight mesh versus standard mesh in the sublay position with closure of the peritoneum, posterior rectus sheath and reconstruction of the line 
alba in hernias larger than $4 \mathrm{~cm}$. The recurrence rate was $17 \%$ for the lightweight mesh and 7\% for the standard mesh (Comparison 02:01: RR 2.31, 95\% CI 0.93 to 5.71; $\mathrm{p}=0.07$ ). No difference was observed between the groups in the frequency of chronic wound pain after 24 months (Comparison 02:02: RR 0.59, 95\% CI 0.15 to 2.40; $\mathrm{p}=0.46$ ), rates of deep infection (Comparison 02:03: RR 0.99, 95\% CI 0.30 to 3.28; p=0.98), hospital stay in days (Comparison 02.04: WMD 0.80, 95\% CI -1.78 to 3.38; $\mathrm{p}=0.54$ ) or operation time in hours (Comparison 02.05: WMD 0.00, 95\% CI -0.21 to 0.21; $\mathrm{p}=1.00$ ). The infections in this study were mostly subcutaneous and no mesh removals were necessary.

\section{The onlay versus sublay mesh positions}

The Köhler 2004 and Baracs 2007 studies investigated the onlay position and sublay positions in mesh repair. In the Köhler 2004 study, the recurrence rate was 10\% for the onlay position and $9 \%$ for the sublay position. The recurrence rates in the Baracs 2007 study were $7.4 \%$ and $13.6 \%$ in the onlay and sublay mesh groups, respectively. The pooled comparison was not significant (Comparison 03:01: RR 0.66, 95\% CI 0.35 to 1.25; $\mathrm{p}=0.21$ ). A post hoc power calculation on these proportions with G*Power software (version 3.03, Kiel, Germany) yielded only a power of $23 \%$._In the Köhler 2004 study the operation time was significantly shorter in the onlay group compared with the sublay group (Comparison 03:02: WMD 22.50, 95\% CI -38.72 to -6.28 ; $\mathrm{p}=0.007)$. In the Baracs 2007 study the mean operation times in the sublay and onlay mesh group were comparable with 72.2 (minimum 25, maximum 210 minutes) and 74.2 (minimum 30, maximum 210 minutes) minutes, respectively. In the Köhler 2004 study no difference was found for hospital stay in days (Comparison 03.03: WMD 0.30, 95\% CI -1.63 to 2.23; p=0.54), for overall complication rate (Comparison 03:04: RR 0.77, 95\% CI 0.35 to 1.68 ; $\mathrm{p}=0.51$ ) or for postsurgical pain on the first postoperative day measured 
with a VAS score (Comparison 03.05: WMD -0.20, 95\% CI -1.03 to 0.63; $\mathrm{p}=0.64$ ). The calculated hazard ratio for recurrences in the Köhler 2004 study was 1.16 (CI 0.31 to 4.3).

\section{Mesh (polypropylene) versus skin autograft in the onlay position}

In a double trial Korenkov 2002a studied mesh (polypropylene) versus skin autograft in the onlay position with closure of the fascia in simple hernias compared to mesh (polypropylene) versus skin autograft in the onlay position in complex hernias ( hernia larger than $10 \mathrm{~cm}$ in diameter or a re-recurrence) with closure of the fascia (Korenkov 2002b). The results of this double trial were pooled. The recurrence rate was $8.6 \%$ for the mesh group and $12.3 \%$ for the skin autograft group (Comparison 04:01: RR 0.70, 95\% CI 0.25 to 1.94; $p=0.49$ ). The calculated hazard ratio for recurrences in the simple hernia group was 0.73 (CI 0.16 to 3.27) compared to 0.56 (CI 0.11 to 2.79) in the complex hernia group. Pooling yielded a hazard ratio of 0.65 (CI 0.22 to $1.93 ; \mathrm{p}=0.43$ ). Pain was significantly less in the skin autograft group (Comparison 04:02: RR 1.94, 95\% CI 1.05 to 3.58; $\mathrm{p}=0.03$ ). This pain outcome was defined as the presence of wound pain measured on a VAS after one year. No difference was found in the cosmetic result (Comparison 04:03: RR 1.18, 95\% CI 0.80 to $1.76 ; \mathrm{p}=0.41$ ) or in the rates of deep infection (Comparison 04:04: RR 0.70, 95\% CI 0.24 to 2.04; $\mathrm{p}=0.52$ ) between the two groups after one year. Four polypropylene meshes had to be removed.

\section{Onlay mesh repair versus double mesh intraperitoneal repair for recurrent large ventral}

\section{hernias}

Afifi 2005 studied the onlay mesh repair versus intraperitoneal double mesh repair. The recurrence rate was $27 \%$ for the onlay mesh group and $0 \%$ for the intraperitoneal mesh group (Comparison 05:01: RR 11.30, 95\% CI 0.68 to 188.39; p=0.09). A non significant difference was found for seroma formation: $32 \%$ in the onlay group and $0 \%$ in the intraperitoneal group 
(Comparison 05:02: RR 13.04, 95\% CI 0.79 to 214.34; p=0.07). A post hoc power calculation on these proportions with G*Power software (version 3.03, Kiel, Germany) showed a power of $58 \%$. No difference was found for chronic postoperative wound pain after 6 months: $4.5 \%$ in the onlay group and 31.6\% in the intraperitoneal group (Comparison 05:07: RR 0.14, 95\% CI 0.02 to 1.09; $\mathrm{p}=0.06$ ). Likewise, no difference was observed between groups in superficial wound infection (Comparison 05:03: RR 0.86, 95\% CI 0.06 to 12.89; p=0.92), wound hematoma (Comparison 05:04: RR 2.61, 95\% CI 0.11 to 60.51; $\mathrm{p}=0.55$ ), deep venous thrombosis (Comparison 05:05: RR 0.29, 95\% CI 0.01 to 6.72; $\mathrm{p}=0.44$ ), fatal pulmonary embolism (Comparison 05:06: RR 0.29, 95\% CI 0.01 to 6.72; $\mathrm{p}=0.44$ ) or mesh removal (Comparison 05:08: RR 2.61, 95\% CI 0.11 to 60.51; p=0.55). Only one mesh was removed from the onlay mesh repair group.

\section{The components separation technique versus the intraperitoneal prosthetic repair in}

\section{giant hernias}

de Vries 2007a studied the components separation technique versus prosthetic repair in giant hernias and found that the closure of the fascia was not possible because of the large defect in the fascia. The recurrence rate was $56 \%$ for the components separation technique and $58 \%$ for the prosthetic repair (Comparison 07:01: RR 0.96, 95\% CI 0.55 to 1.69; $\mathrm{p}=0.89$ ). The calculated hazard ratio for recurrences was 0.79 (CI 0.34 to 1.86). No difference was found for reoperations due to wound complications (Comparison 07:02: RR 0.30, 95\% CI 0.07 to 1.26; $\mathrm{p}=0.10$ ). The seven reoperations for wound complications in the mesh repair group were removals of infected meshes. Differences in the operation time could not be analyzed because the standard deviations were not published, although the authors stated that the operation time was significantly shorter in the components separation technique group. 


\section{DISCUSSION}

This review has included data from seven trials. One trial made comparisons between three different types of hernia repairs (Korenkov 2002a). When considering the comparison of direct suture repair versus mesh repair, only three randomized trials were found (Burger 2004; Korenkov 2002a; Baracs 2007). Mesh repair was associated with fewer hernia recurrences and with more infection compared with direct suture repair. Most surgeons seem to have accepted the superiority of mesh repair for an average patient. For example, in a population based study of 10,822 patients in the USA Flum 2003 observed an increase in the frequency of synthetic mesh use from 35\% in 1987 to $65 \%$ by 1999. The NNTb was 6 patients for recurrences and the NNTh was 10 patients for infection. Thus, for every six mesh repairs, one recurrence is prevented in comparison with direct suture repair, but one infection is seen for every 10 mesh repairs. Therefore, the balance between the benefit of a lower recurrence rate and the risk of a higher wound infection rate should be considered. Another minor consideration that has to be made are the additional direct costs of the mesh. In a Swedish observational study, however, the total costs (including sick leave costs) of open mesh repair were not higher than the costs of open suture repair (Israelsson 2003).

These three studies comparing suture repair with mesh repair included small hernias which were defined as being smaller than $10 \mathrm{~cm}$, smaller than $6 \mathrm{~cm}$ and smaller than $25 \mathrm{~cm} 2$, respectively. So these studies also included hernias smaller than $4 \mathrm{~cm}$, which had for instance a lower recurrence rate in a retrospective observational study with the suture technique (Hesselink 1993). In an experts' meeting it was recommended to use fascia-duplication only in small incisional hernias (Korenkov 2001). These different hernia sizes in the included studies are a source of clinical heterogeneity. In large incisional hernias the NNTb for recurrences is probably higher. However in the study of Burger 2004 a subgroup analysis of 50 patients with 
hernias smaller than $10 \mathrm{~cm} 2$ showed a significant different 10 years recurrence rate of $67 \%$ after suture repair and 17\% after mesh repair.

A comparison of different types of synthetic mesh or the use of a skin autograft was performed by Conze 2005 and Korenkov 2002a. Conze 2005 compared lightweight mesh and standard mesh in the sublay position. Although not significant, there was a trend towards more recurrences in the lightweight mesh group, which the authors explained as a technically related difference. Korenkov 2002a compared standard mesh (polypropylene) with skin autograft in the onlay position in simple ventral hernias and in complex hernias. No differences were found for the recurrence rate, satisfaction with cosmetic result and infection. Chronic wound pain was significantly more frequent in the mesh group than in the skin autograft group.h

Afifi 2005 compared the onlay position with the intraperitoneal position. Fewer hernia recurrences and seroma formations were observed in the intraperitoneal group, although the 95\% confidence intervals were large and insignificant. This study lacked power to find a significant difference in recurrence rate.

Köhler 2004 and Baracs 2007 studied the onlay and the sublay mesh positions. The recurrence rate was not different, however the operation time was shorter in the onlay group in the Köhler 2004 study, but equal in the Baracs 2007 study. Also this studies lacked power to find a significant difference in recurrence rate.

In comparing the onlay and sublay positions, we are comparing the different positions of the mesh, but also the difference in fascia closure. In the onlay position, the fascia remains open (Burger 2004) or is closed in one layer (linea alba), while in the sublay position, the fascia is closed in two layers (anterior and posterior rectal sheath).

A study by de Vries 2007a compared the components separation technique with intraperitoneal prosthetic repair in giant hernias. The recurrence rates were high and equal in 
both groups. The recurrence rate in the intraperitoneal group (58\%) was not comparable with that found in Afifi's study (recurrence rate $0 \%$ ), as the size of the hernia defect was different, the fascia closure was different and the 95\% confidence intervals in Afiifi's study were large and insignificant.

In all included studies, the direct suture repairs were inappropriately described. For instance the different possibilities in direct closure technique such as the use of which suture material (absorbable versus non-absorbable or slowly absorbable), continuous versus interrupted closure of the fascia, suture to wound length ratio and in relation with this ratio the size and interval of the fascial bites, were incompletely described. Furthermore, recurrences were not objectively defined and were generally diagnosed by clinical examination rather than through imaging techniques.

Infection was either not objectively defined or was not comparable between the different studies, such as the distinction between superficial and deep graft infection. The same critique can be used for pain, either wound pain or abdominal pain. For example, Burger 2004 found a significant difference in abdominal pain but not in wound pain.

The limited number of available trials has resulted in an inadequate comparison of the different techniques for ventral hernia repair. Thus, more randomized trials are needed.

\section{AUTHORS' CONCLUSIONS}

\section{Implications for practice}

There is good evidence from three trials included in this review that open mesh repair is superior to suture repair in terms of recurrences, but inferior in the occurrence of wound infection. There is insufficient evidence from five trials in this review as to which type of 
mesh or which position of the mesh (on- or sublay) should be used in open ventral hernia repair. Also, insufficient evidence was found to advocate the use of the components separation technique.

\section{Implications for research}

Given its ongoing use, further randomized trials of high methodological rigor are needed in order to define the true extent of benefit from the use of different types of mesh and the different positions the mesh are placed. Further trials are needed to study the newer bioprosthetic meshes (de Vries 2007b). Specifically, more information and research is needed to compare more complicated abdominal wall reconstructions with mesh repair. Further information is needed to delineate the relationship between clinical and radiological recurrences, and to determine the most appropriate measure of functional outcomes that relate to a generic measure of health-related quality of life and the outcome pain in relation with the use of different types of mesh.

\section{Acknowledgements}

The Cochrane Colorectal Cancer Group and peer reviewers are acknowledged for their assistance with this review. 


\section{REFERENCES}

\section{References to studies included in this review}

\section{Afifi 2005 \{published data only\}}

* Afifi RY. A prospective study between two different techniques for the repair of a large recurrent ventral hernia: a double mesh intraperitoneal repair versus onlay mesh repair. Hernia 2005;9:310-5.

\section{Baracs 2007 \{published data only\}}

* Baracs J,Weber G, Takacs I,Horvath OP. Results of openmesh versus suture repair in treatment of abdominal wall hernias (multicentric, prospective, randomised, internet-based, clinical trial. Poster 29th International Congress of the European Hernia Society; 2007 May 6-9; Athens (Greece). 2007.

Weber G, Horvath OP. Results of ventral hernia repair: comparison of suture repair with mesh implantation (onlay vs sublay) using open and laparoscopic approach--prospective, randomized, multicenter study. Magy Seb 2002;55(5):285-9.

\section{Burger 2004 \{published data only\}}

* Burger JWA, Luijendijk RW, Hop WCJ, Halm JA, Verdaasdonk EGG, Jeekel J. Long-term follow-up of a randomized controlled trial of suture versus mesh repair of incisional hernia. Annals of Surgery 2004;240:578-85.

Luijendijk RW, HopWC, van den Tol MP, de Lange DC, Braaksma MM, IJzermans JN, Boelhouwer RU, de Vries BC, Salu MK, Wereldsma JC, Bruijninckx CM, Jeekel JJ. A comparison of suture 
repair with mesh repair for incisional hernia. $N$ Engl JMed 2000;343

(6):392-8.

\section{Conze 2005 \{published data only\}}

* Conze J, Kingsnorth AN, Flament JB, Simmermacher R, Arlt G, Langer C, Schippers E, Hartley M, Schumpelick V. Randomized clinical trial comparing lightweight composite mesh with polyester or polypropylene mesh for incisional hernia repair. British Journal of Surgery 2005;92(12):1488-93.

\section{de Vries 2007a \{published data only\}}

* De Vries TS, van Goor H, Charbon JA, Rosman C, Hesselink EJ, van der Wilt GJ, Bleichrodt RP. Repair of giant midline abdominal wall hernias: "components separation technique” versus prosthetic repair. World Journal of Surgery 2007;31:756-63.

\section{Korenkov 2002a \{published data only\}}

* Korenkov M, Sauerland S, ArndtM, Bograd L, Neugebauer EAM, Troidl H. Randomized clinical trial of suture repair, polypropylene mesh or autodermal hernioplasty for incisional hernia. British Journal of Surgery 2002;89:50-6.

\section{Korenkov 2002b \{published data only\}}

* Korenkov M, Sauerland S, ArndtM, Bograd L, Neugebauer EAM, Troidl H. Randomized clinical trial of suture repair, polypropylene mesh or autodermal hernioplasty for incisional hernia. British Journal of Surgery 2002;89:50-6.

\section{Köhler 2004 \{published data only\}}

* Köhler L, Sauerland S, Meyer A, Saad S, Schüller BK, Knaebel 
HP, Seiler CM. Mesh implantation in onlay- or sublay- technique

for closure of median ventral hernias: first results of a randomized

clinical trial [Netzimplantation in Onlay- oder Sublay- Technik zum

Verschluss medianer Bauchwandhernien: erste Ergebnisse einer randomisierten

klinishen Studie]. Poster presented at the Congress of

the German Surgical Association. 2005.

\section{References to studies excluded from this review}

\section{Schumpelick 1999 \{published data only\}}

* Schumpelick V, Klosterhalfen B, Müller M, Klinge U. Minimized

polypropylene mesh for preperitoneal net plasty (PNP) of incisional hernias [Minimierte Polypropylen-Netze zur präperitonealen Netzplastik (PNP) der Narbenhernie]. Chirurg 1999;70:422-30.

\section{Additional references}

\section{Amid 1997}

Amid PK. Classification of biomaterials and their related complications in abdominal wall hernia surgery. Hernia 1997;1:15-21.

\section{Brown 2005}

Brown SR, Goodfellow PB. Transverse verses midline incisions

for abdominal surgery. Cochrane Database of Systematic

Reviews 2005, Issue 4. [Art. No.: CD005199. DOI:

10.1002/14651858.CD005199.pub2]

\section{Burger 2005}

Burger JWA, Lange JF,HalmJA, Kleinrensink GJ, Jeekel J. Incisional 
hernia: early complication of abdominal surgery. World Journal of Surgery 2005;29(12):1608-13.

\section{Cassar 2005}

Cassar K, Munro A. Surgical treatment of incisional hernia. British Journal of Surgery 2002;89:534-45.

\section{de Vries 2007b}

de Vries Reilingh TS, Bodegom ME, van Goor H, Hartman EH, van der Wilt GJ, Bleichrodt RP. Autologous tissue repair of large abdominal wall defects. Br J Surg 2007;94(7):791-803.

\section{Deeks 2005}

Deeks JJ, Higgins JPT, Altman DG, editors. Analysing and presenting results. In Higgens JPT, Greeen S, editors. Cohrane Handbook for Systematic Reviews of Interventions 4.2.5 [updated May 2005]; Section 8. In: The Cochrane Library, Issue 3, 2005. Chichester, UK: JohnWiley \& Sons, Ltd, 2005.

\section{Flum 2003}

FlumDR,Horvath K,KoepsellT.Have outcomes of incisional hernia repair improved with time? A population-based analysis. Ann Surg 2003;237(1):129-35.

\section{Hesselink 1993}

Hesselink VJ, Luijendijk RW, de Wilt JH, Heide R, Jeekel J. An evaluation of risk factors in incisional hernia recurrence. Surg Gynecol Obstet 1993;176(3):228-234.

\section{Higgins 2005}

Higgins JPT, Green S, editors. Cochrane Handbook for Systematic 
Reviews of Interventions 4.2.5 [updated May 2005].. In: The

Cochrane Library. Chichester, UK: John Wiley \& Sons, Ltd, 2005.

Israelsson 2003

Israelsson LA, Jönsson L,Wimo A. Cost analysis of incisional hernia repair by suture or mesh. Hernia 2003;7:114-7.

Open surgical procedures for incisional hernias (Review) 8

Copyright (C) 2008 The Cochrane Collaboration. Published by JohnWiley \& Sons, Ltd.

\section{Klinge 2000}

Klinge U, Si ZY, Zheng H, et al.Abnormal collagen I to III distribution in the skin of patients with incisional hernia. European Surgical Research 2000;32(1):43-8.

\section{Klinge 2001}

Klinge U, Si ZY, Zheng H, et al.Collagen I/III and matrix metalloproteinases (MMP) 1 and 13 in the fascia of patients with incisional hernias. Journal of Investigative Surgery 2001;14(1):47-54.

\section{Korenkov 2001}

Korenkov M, Paul A, Sauerland S, Neugebauer E, ArndtM, Chevrel JP, Corcione F, Fingerhut A, Flament JB, KuxM,Matzinger A,Myrvold HE, Rath AM, Simmermacher RKJ. Classification and surgical treatment of incisional hernia. Results of an experts' meeting. Langenbeck's Archives of Surgery 2001;386:65-73.

\section{Luijendijk 2000}

Luijendijk RW, HopWC, van den Tol MP, de Lange DC, Braaksma MM, IJzermans JN, Boelhouwer RU, de Vries BC, Salu MK, Wereldsma JC, Bruijninckx CM, Jeekel JJ. A comparison of suture 
repair with mesh repair for incisional hernia. $N$ Engl J Med 200;343

(6):392-8.

\section{Parmar 1998}

Parmar MKB, Torri V, Stewart L. Extracting summary statistics to perform meta-analyses of the published literature for survival endpoints.

Statistics in Medicine 1998;17:2815-2834.

\section{Paul 1998}

Paul A, Korenkov M, Peters S, Köhler L, Fischer S, Troidl H. Unacceptable results of the Mayo procedure for repair of abdominal incisional hernias. European Journal of Surgery 1998;164:361-7.

\section{Pollock 1989}

Pollock AV, Evans M. Early prediction of late incisional hernias. $\mathrm{Br}$ J Surg 1989;76(9):953-4.

\section{Weber 2002}

Weber G, Horvath OP. Results of ventral hernia repair: comparison of suture repair with mesh implantation (onlay vs sublay) using open and laparoscopic approach--prospective, randomized, multicenter study. Magy Seb 2002;55(5):285-9.

* Indicates the major publication for the study 


\section{Data and analyses}

\section{Suture repair versus mesh repair}

\begin{tabular}{|c|c|c|c|c|}
\hline Outcome or Subgroup & Studies & Participant & Statistical Method & Effect Estimate \\
\hline 1.1 Recurrence & 3 & 445 & $\begin{array}{l}\text { Risk Ratio (M-H, Fixed, } \\
95 \% \text { CI) }\end{array}$ & $1.85[1.33,2.56]$ \\
\hline 1.2 Pain & 2 & 180 & $\begin{array}{l}\text { Risk Ratio (M-H, Fixed, } \\
\text { 95\% CI) }\end{array}$ & $1.02[0.62,1.68]$ \\
\hline $\begin{array}{l}1.3 \text { Satisfied with cosmetic } \\
\text { result }\end{array}$ & 2 & 167 & $\begin{array}{l}\text { Risk Ratio (M-H, Fixed, } \\
\text { 95\% CI) }\end{array}$ & $0.90[0.68,1.20]$ \\
\hline 1.4 Infection & 2 & 198 & $\begin{array}{l}\text { Risk Ratio (M-H, Fixed, } \\
\text { 95\% CI) }\end{array}$ & $0.09[0.01,0.70]$ \\
\hline
\end{tabular}

\section{Lightweight mesh versus standard mesh in sublay position}

Outcome or Subgroup Studies Participants Statistical Method Effect Estimate

\begin{tabular}{|c|c|c|c|c|}
\hline 2.1 Recurrence & 1 & 165 & $\begin{array}{l}\text { Risk Ratio (M-H, Fixed, } \\
\text { 95\% CI) }\end{array}$ & $2.31[0.93,5.71]$ \\
\hline 2.2 Pain & 1 & 165 & $\begin{array}{l}\text { Risk Ratio (M-H, Fixed, } \\
\text { 95\% CI) }\end{array}$ & $0.59[0.15,2.40]$ \\
\hline 2.3 Deep infection & 1 & 165 & $\begin{array}{l}\text { Risk Ratio (M-H, Fixed, } \\
\text { 95\% CI) }\end{array}$ & $0.99[0.30,3.28]$ \\
\hline 2.4 Hospital stay in days & 1 & 165 & $\begin{array}{l}\text { Mean Difference (IV, } \\
\text { Fixed, 95\% CI) }\end{array}$ & $0.80[-1.78,3.38]$ \\
\hline 2.5 Operation time in hours & 1 & 165 & $\begin{array}{l}\text { Mean Difference (IV, } \\
\text { Fixed, 95\% CI) }\end{array}$ & $0.00[-0.21,0.21]$ \\
\hline
\end{tabular}

\section{Onlay versus sublay mesh}

Outcome or Subgroup Studies Participants Statistical Method Effect Estimate

\begin{tabular}{|c|c|c|c|c|}
\hline 3.1 Recurrence & 2 & 353 & $\begin{array}{l}\text { Risk Ratio (M-H, Fixed, } \\
95 \% \text { CI) }\end{array}$ & $0.66[0.35,1.25]$ \\
\hline $\begin{array}{l}3.2 \text { Operation time in } \\
\text { minutes }\end{array}$ & 1 & 93 & $\begin{array}{l}\text { Mean Difference (IV, } \\
\text { Fixed, 95\% CI) }\end{array}$ & $\begin{array}{l}-22.50[-37.74,- \\
7.26]\end{array}$ \\
\hline 3.3 Hospital stay in days & 1 & 93 & $\begin{array}{l}\text { Mean Difference (IV, } \\
\text { Fixed, 95\% CI) }\end{array}$ & $0.30[-1.63,2.23]$ \\
\hline $\begin{array}{l}3.4 \text { Overall complication } \\
\text { rate }\end{array}$ & 1 & 93 & $\begin{array}{l}\text { Risk Ratio (M-H, Fixed, } \\
95 \% \text { CI) }\end{array}$ & $0.77[0.35,1.68]$ \\
\hline
\end{tabular}




\section{Mesh (polypropylene) versus skin autograft in onlay position}

Outcome or Subgroup Studies Participants Statistical Method Effect Estimate
4.1 Recurrence
2
127
Risk Ratio (M-H, Fixed,
$0.70[0.25,1.94]$ 95\% CI)
4.2 Pain
$2 \quad 103$
Risk Ratio (M-H, Fixed, 95\% CI)
4.3 Satisfied with cosmetic 2
79 Risk Ratio (M-H, Fixed, 95\% CI) result
4.4 Deep infection
2
127 Risk Ratio (M-H, Fixed, 95\% CI)
1.94 [1.05, 3.58]
$1.18[0.80,1.76]$
$0.70[0.24,2.04]$

\section{Onlay mesh repair versus double mesh intraperitoneal repair}

\begin{tabular}{|c|c|c|c|c|}
\hline Outcome or Subgroup & Studies & Participant & Statistical Method & Effect Estimate \\
\hline 5.1 Recurrence & 1 & 41 & $\begin{array}{l}\text { Risk Ratio (M-H, Fixed, } \\
\text { 95\% CI) }\end{array}$ & $\begin{array}{l}11.30[0.68 \\
188.39]\end{array}$ \\
\hline 5.2 Seroma & 1 & 41 & $\begin{array}{l}\text { Risk Ratio (M-H, Fixed, } \\
\text { 95\% CI) }\end{array}$ & $\begin{array}{l}13.04[0.79 \\
214.34]\end{array}$ \\
\hline $\begin{array}{l}5.3 \text { Superficial wound } \\
\text { infection }\end{array}$ & 1 & 41 & $\begin{array}{l}\text { Risk Ratio (M-H, Fixed, } \\
\text { 95\% CI) }\end{array}$ & $0.86[0.06,12.89]$ \\
\hline 5.4 Wound hematoma & 1 & 41 & $\begin{array}{l}\text { Risk Ratio (M-H, Fixed, } \\
\text { 95\% CI) }\end{array}$ & $2.61[0.11,60.51]$ \\
\hline $\begin{array}{l}5.5 \text { Deep venous } \\
\text { thrombosis }\end{array}$ & 1 & 41 & $\begin{array}{l}\text { Risk Ratio (M-H, Fixed, } \\
\text { 95\% CI) }\end{array}$ & $0.29[0.01,6.72]$ \\
\hline $\begin{array}{l}5.6 \text { Fatal pulmonary } \\
\text { embolism }\end{array}$ & 1 & 41 & $\begin{array}{l}\text { Risk Ratio (M-H, Fixed, } \\
\text { 95\% CI) }\end{array}$ & $0.29[0.01,6.72]$ \\
\hline $\begin{array}{l}5.7 \text { Postoperative pain (> } 6 \\
\text { mths) }\end{array}$ & 1 & 41 & $\begin{array}{l}\text { Risk Ratio (M-H, Fixed, } \\
\text { 95\% CI) }\end{array}$ & $0.14[0.02,1.09]$ \\
\hline 5.8 Mesh removal & 1 & 41 & $\begin{array}{l}\text { Risk Ratio (M-H, Fixed, } \\
\text { 95\% CI) }\end{array}$ & $2.61[0.11,60.51]$ \\
\hline
\end{tabular}




\section{Components separation technique versus intraperitoneal prosthetic repair (giant hernias)}

\section{Outcome or Subgroup Studies Participants Statistical Method Effect Estimate}

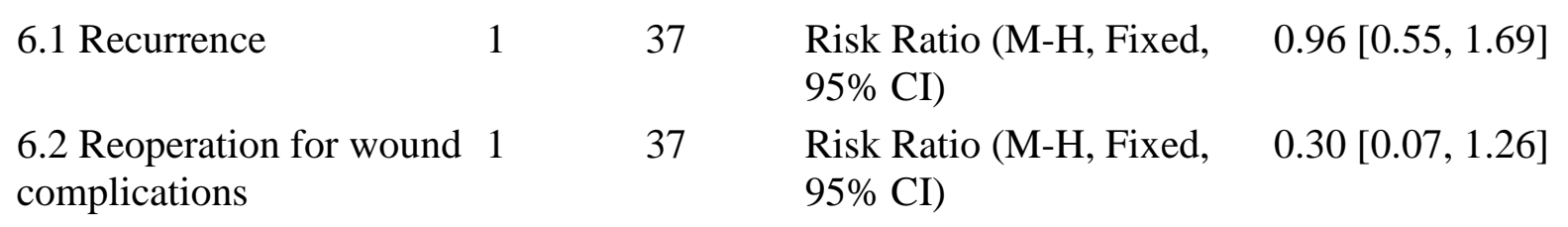

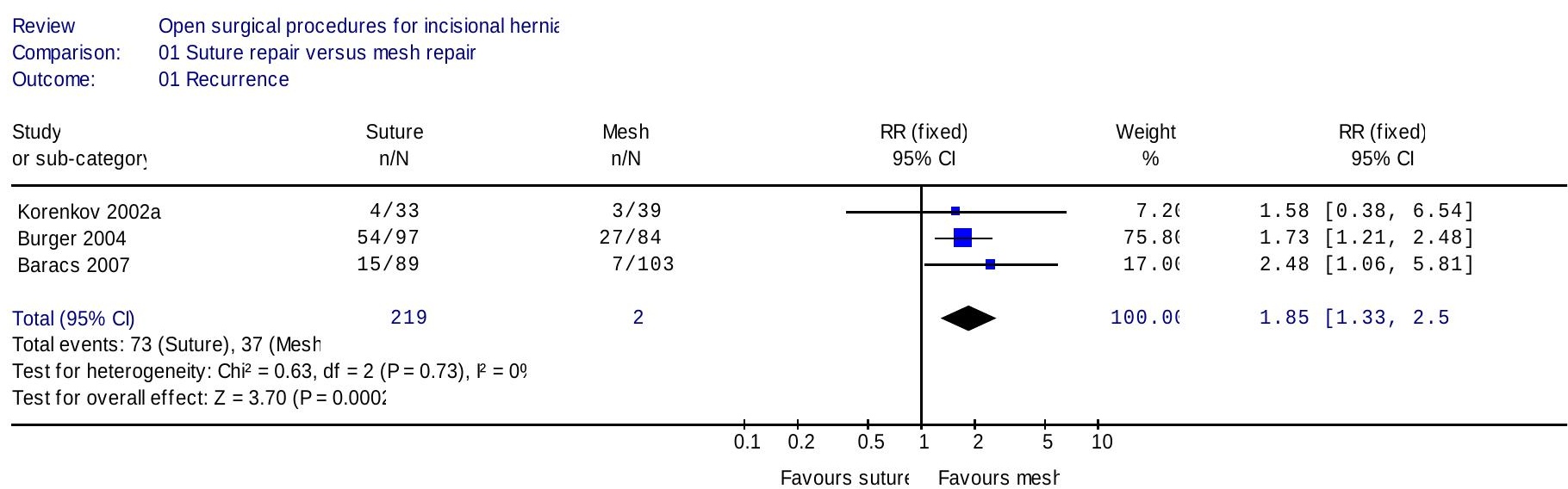

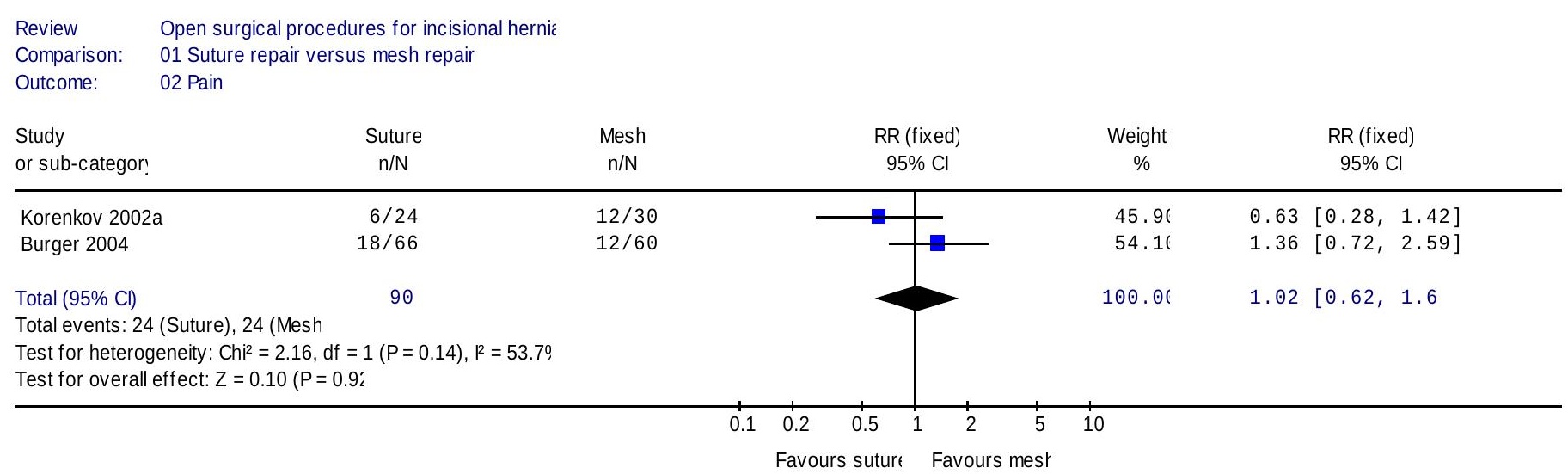


Review Open surgical procedures for incisional hernic

Comparison: 01 Suture repair versus mesh repair

Outcome: $\quad 03$ Satisfied w ith cosmetic result

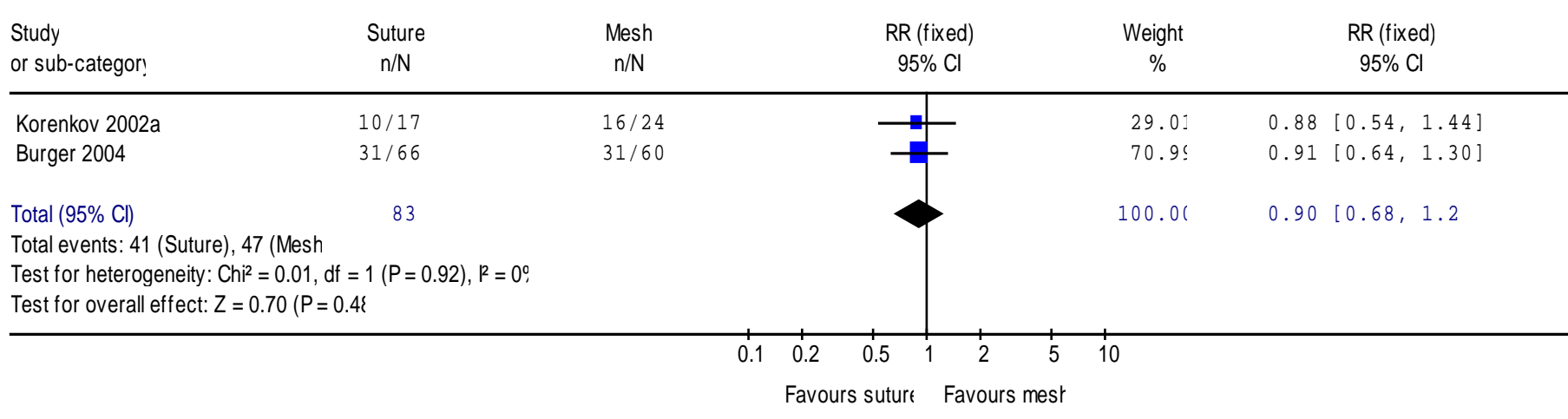

Review Open surgical procedures for incisional hernic

Comparison: 01 Suture repair versus mesh repair

Outcome: 04 Infection

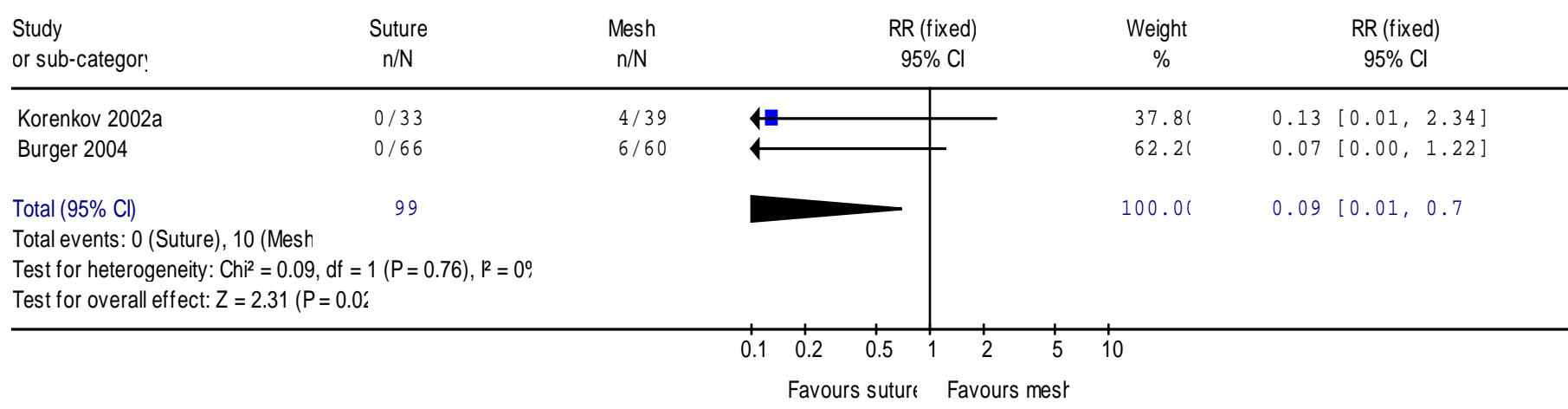

Review Open surgical procedures for incisional hernić

Comparison: 02 Lightw eight mesh versus standard mesh in sublay position

Outcome: $\quad 01$ Recurrence

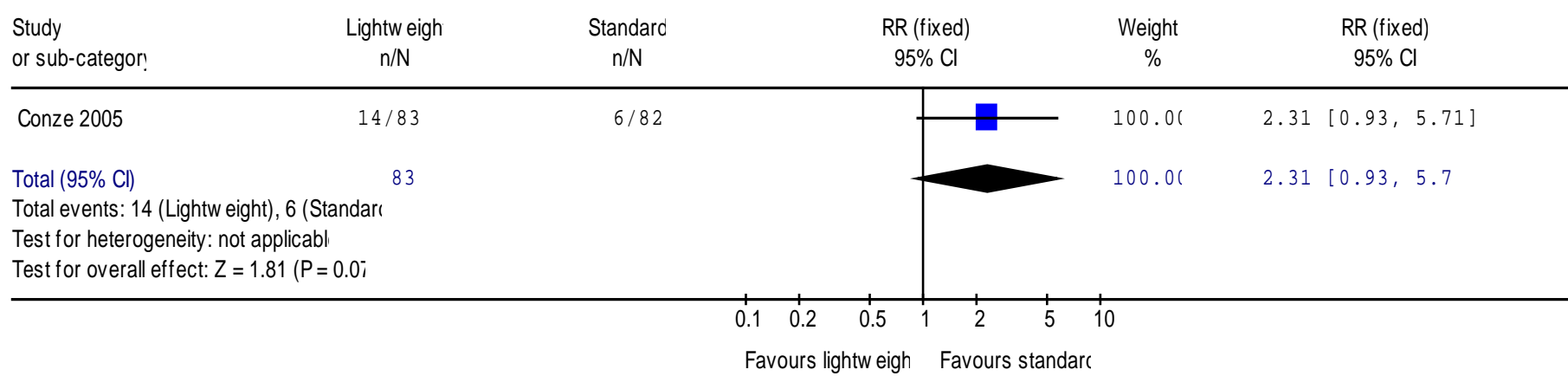


Review Open surgical procedures for incisional hernic

Comparison: 02 Lightw eight mesh versus standard mesh in sublay position

Outcome: $\quad 02$ Pain

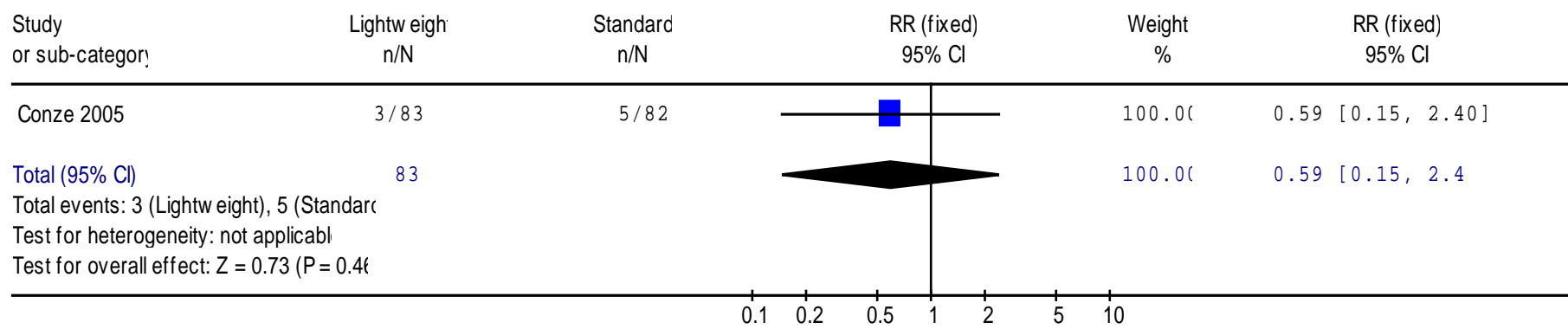

Favours lightweigh Favours standarc

Review Open surgical procedures for incisional hernic

Comparison: 02 Lightw eight mesh versus standard mesh in sublay position

Outcome: $\quad 03$ Deep infection

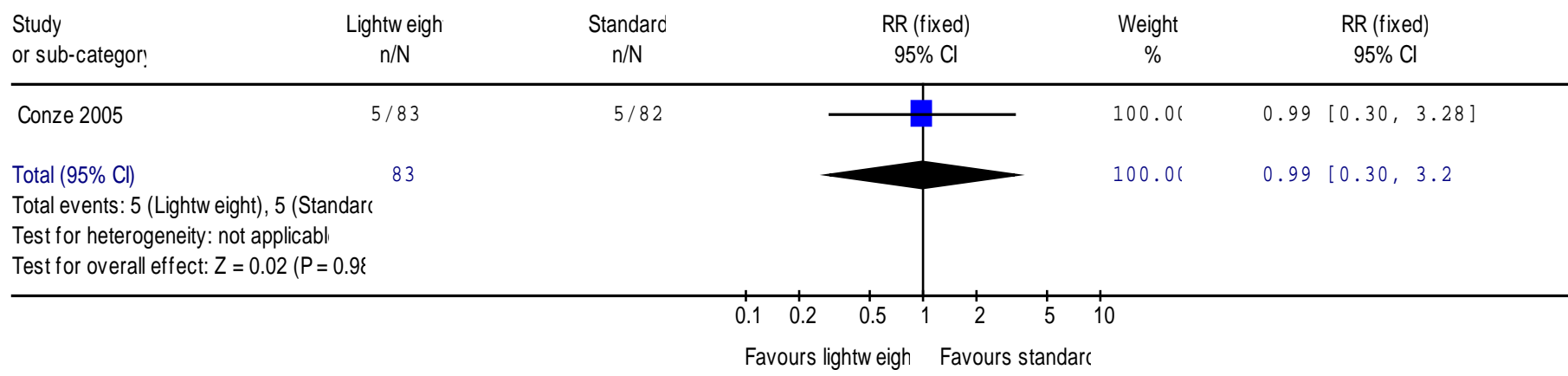

Review Open surgical procedures for incisional hernic

Comparison: 02 Lightw eight mesh versus standard mesh in sublay position

Outcome: $\quad 04$ Hospital stay in days

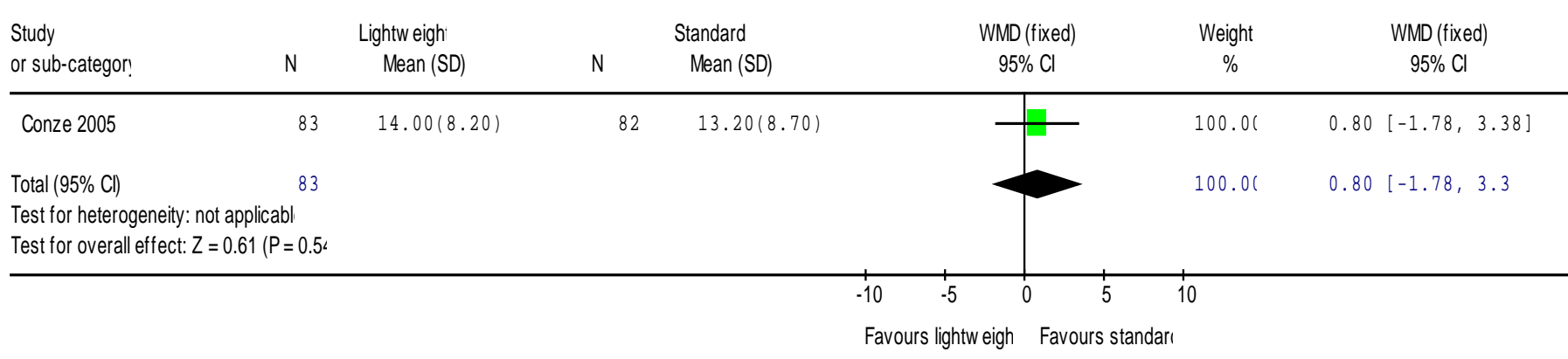


Review Open surgical procedures for incisional hernic

Comparison: 02 Lightw eight mesh versus standard mesh in sublay position

Outcome: $\quad 05$ Operation time in hours

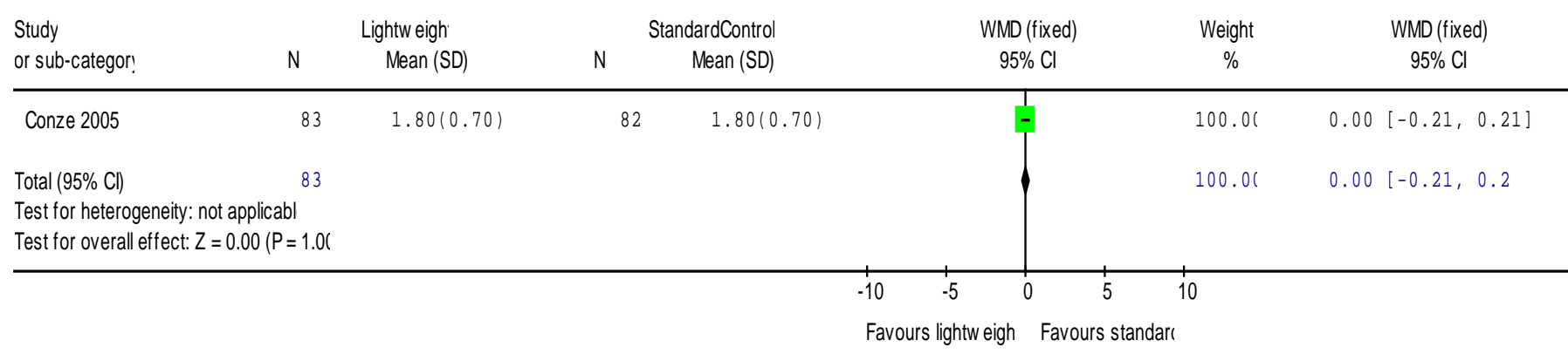

Review Open surgical procedures for incisional hernic

Comparison: 03 Onlay versus sublay mesh

Outcome: 01 Recurrence

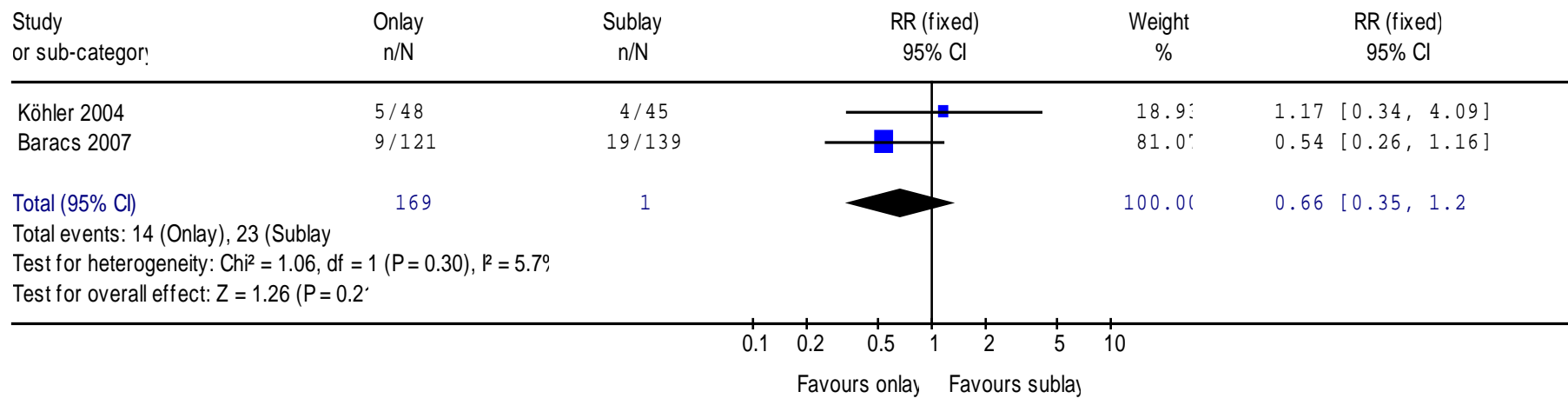

Review Open surgical procedures for incisional hernic

Comparison: $\quad 03$ Onlay versus sublay mesh

Outcome: $\quad 02$ Operation time in minutes

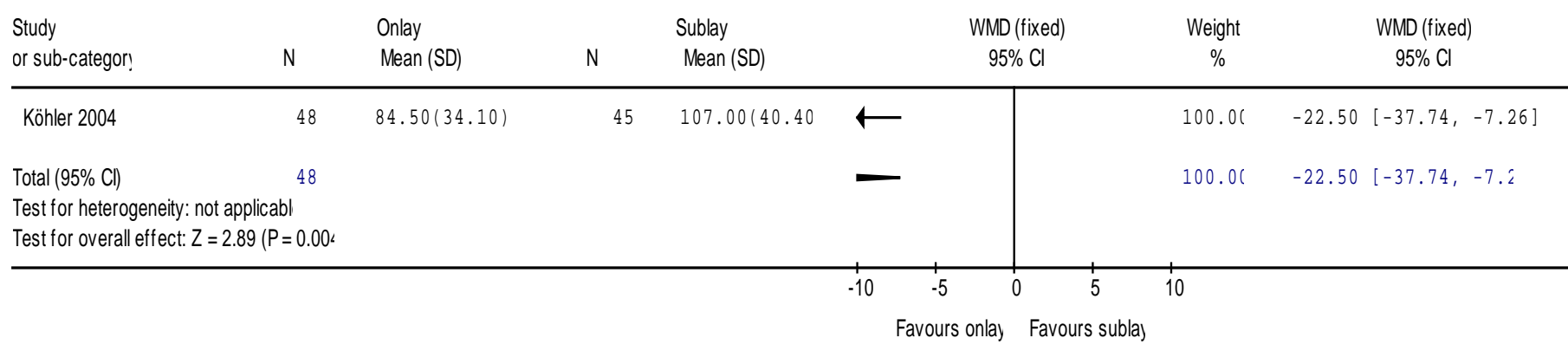


Review Open surgical procedures for incisional hernic

Comparison: 03 Onlay versus sublay mesh

Outcome: $\quad 03$ Hospital stay in days

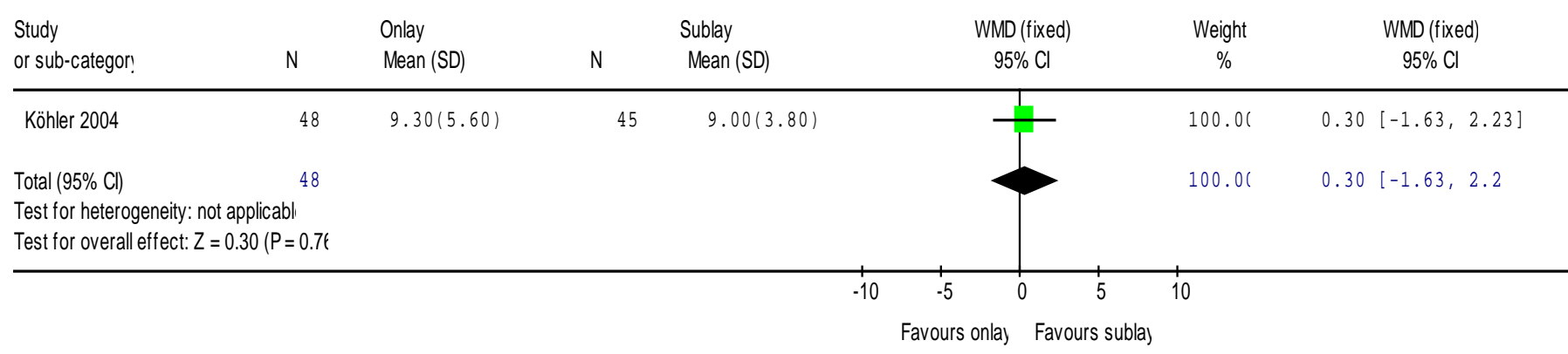

Review Open surgical procedures for incisional hernic

Comparison: 03 Onlay versus sublay mesh

Outcome: $\quad 04$ Overall complication rate

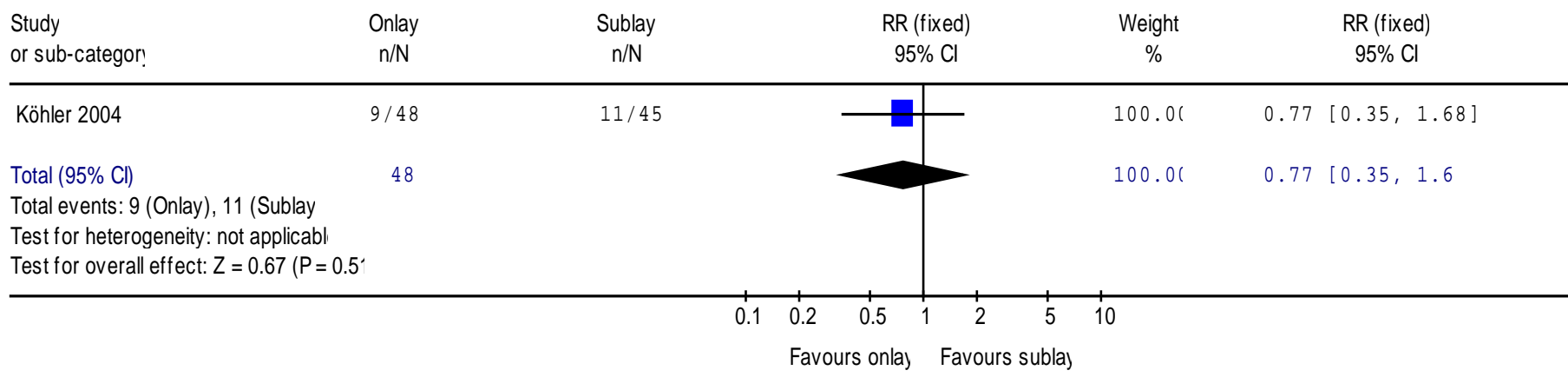

Review Open surgical procedures for incisional hernic

Comparison: 03 Onlay versus sublay mesh

Outcome: $\quad 05$ Postsurgical pain

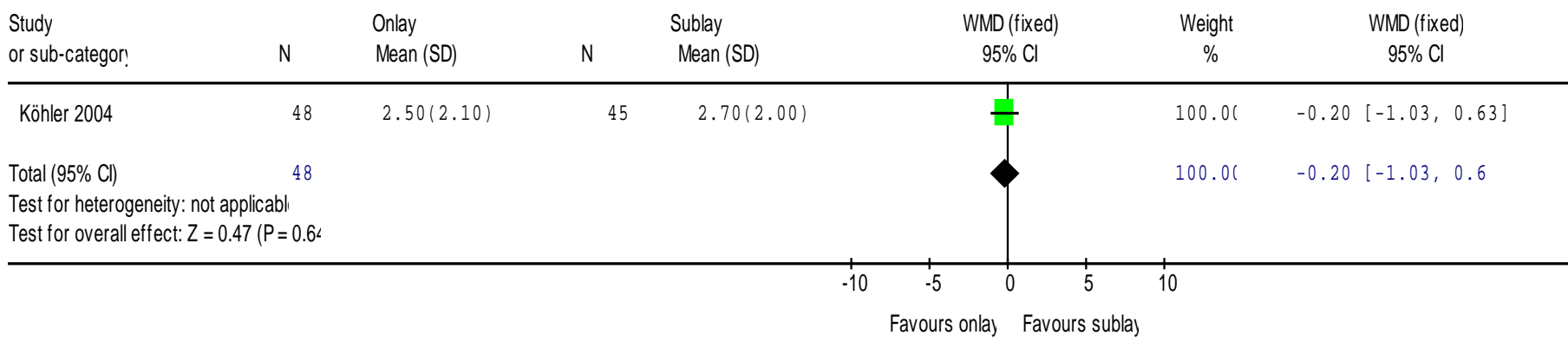


Review Open surgical procedures for incisional hernic

Comparison: 04 Mesh (polypropylene) versus skin autograft in onlay position

Outcome: 01 Recurrence

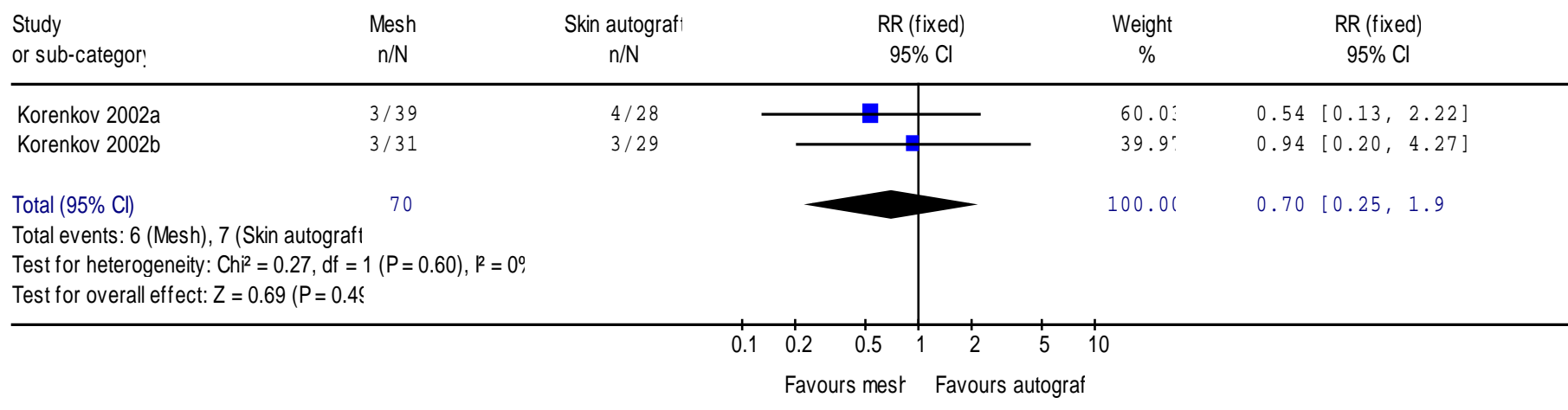

Review Open surgical procedures for incisional hernic

Comparison: 04 Mesh (polypropylene) versus skin autograft in onlay position

Outcome: $\quad 02$ Pain

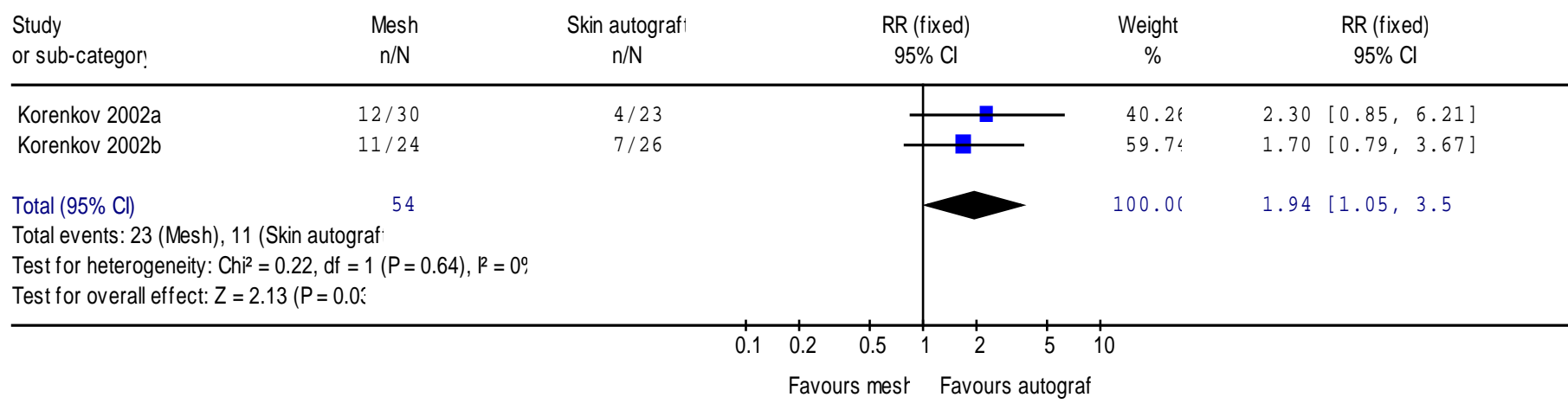

Review Open surgical procedures for incisional hernic

Comparison: 04 Mesh (polypropylene) versus skin autograft in onlay position

Outcome: $\quad 03$ Satisfied with cosmetic result

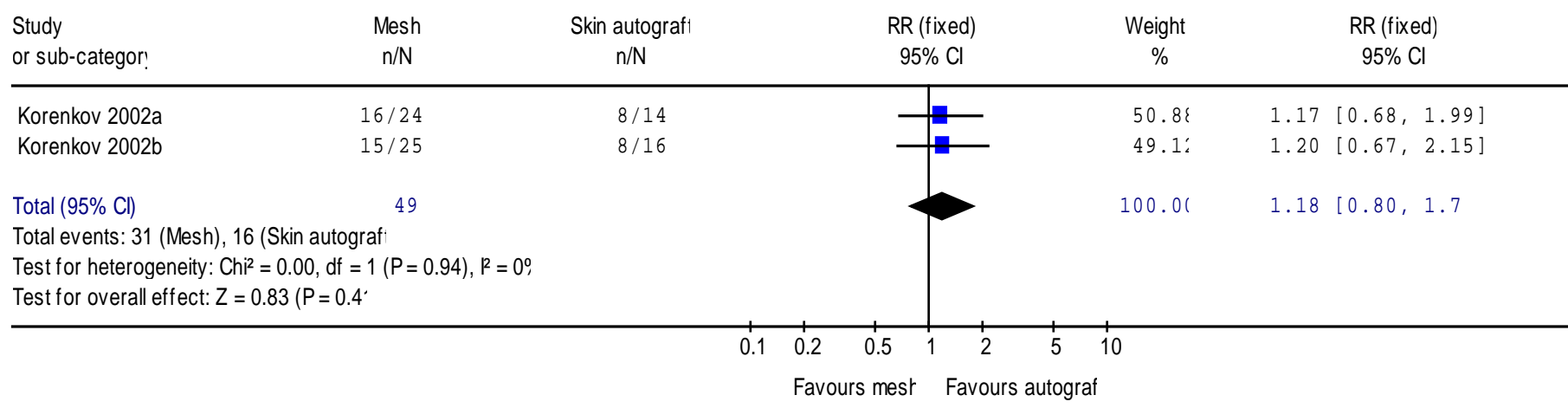


Review Open surgical procedures for incisional hernic

Comparison: 04 Mesh (polypropylene) versus skin autograft in onlay position

Outcome: $\quad 04$ Deep infection

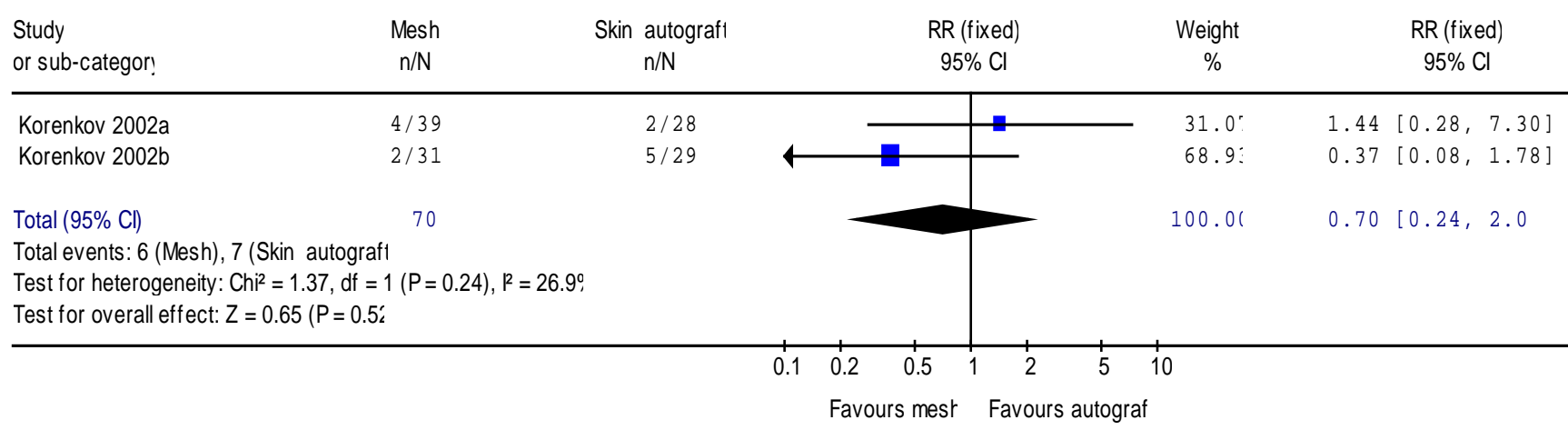

Review Open surgical procedures for incisional hernic

Comparison: 05 Onlay mesh repair versus double mesh intraperitoneal repair

Outcome: 01 Recurrence

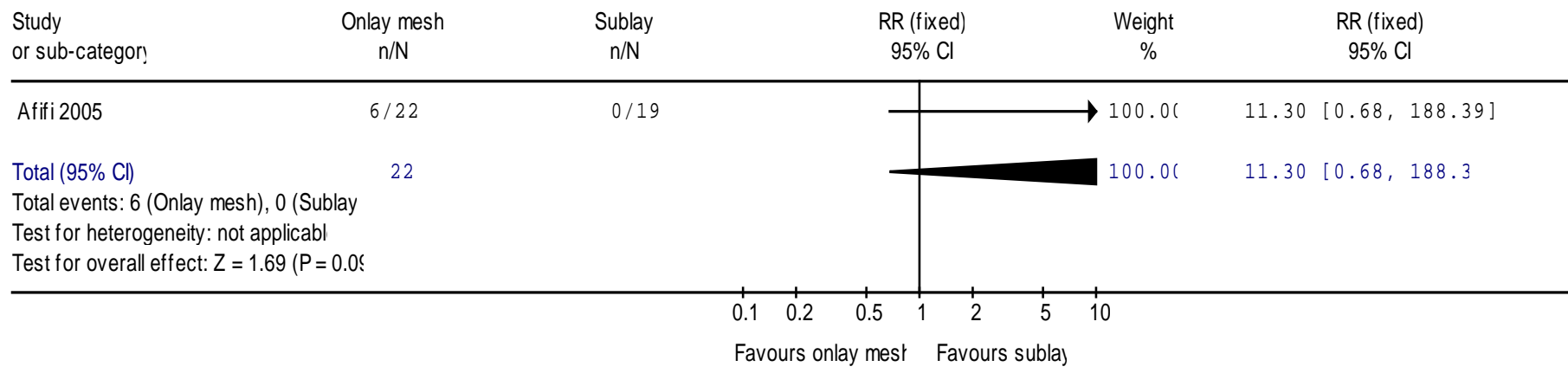


Review Open surgical procedures for incisional hernic

Comparison: 05 Onlay mesh repair versus double mesh intraperitoneal repair

Outcome: $\quad 02$ Seroma

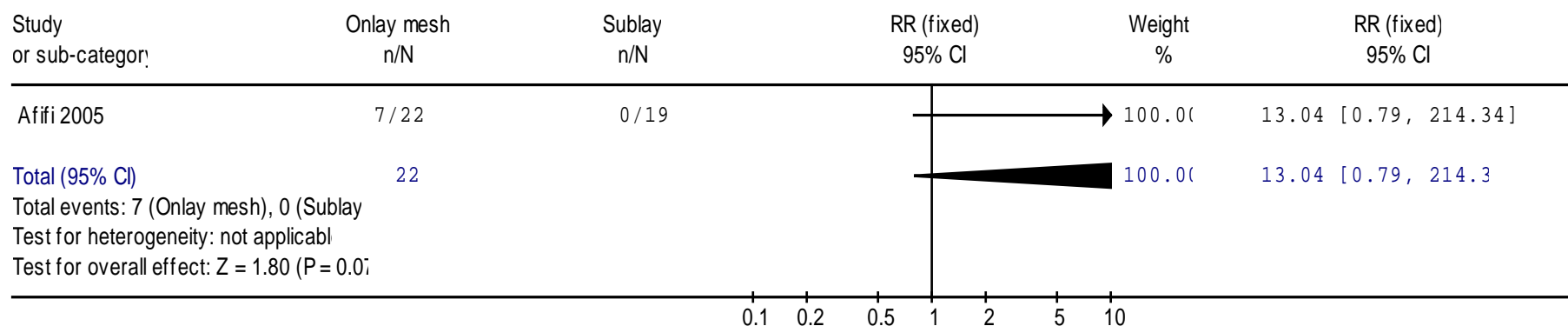

Review Open surgical procedures for incisional hernic

Favours onlay mest Favours subla)

Comparison: 05 Onlay mesh repair versus double mesh intraperitoneal repair

Outcome: $\quad 03$ Superficial w ound infection

$\begin{array}{lll}\text { Study } & \text { Onlay mesh } & \text { RR (fixed) W }\end{array}$

or sub-categor! $\quad \mathrm{n} / \mathrm{N} \quad \mathrm{n} / \mathrm{N} \quad 95 \% \mathrm{Cl} \quad 95 \% \mathrm{Cl}$

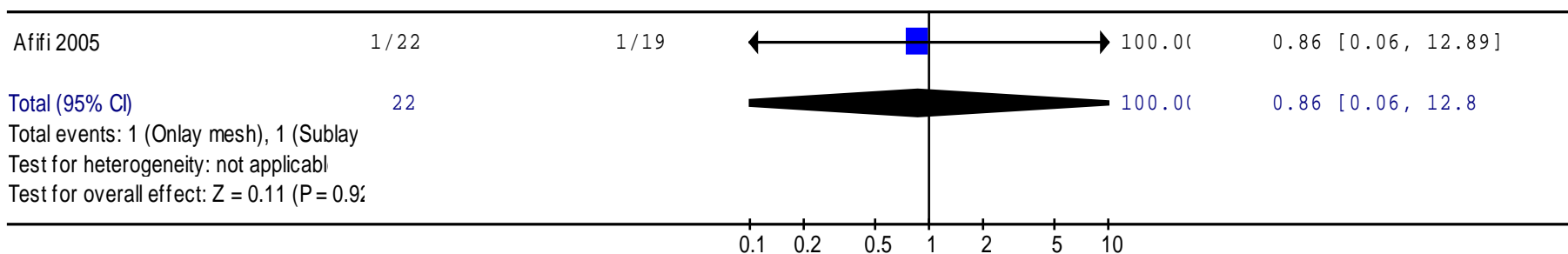

Review Open surgical procedures for incisional hernic

Favours onlay mest Favours sublas

Comparison: $\quad 05$ Onlay mesh repair versus double mesh intraperitoneal repair

Outcome: $\quad 04$ Wound hematoma

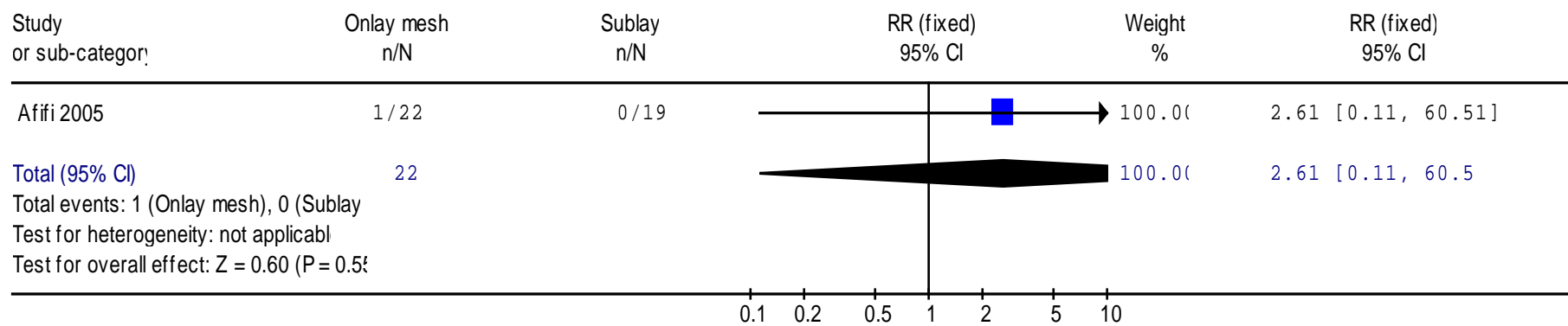

Review Open surgical procedures for incisional hernic

Favours onlay mest Favours subla)

Comparison: 05 Onlay mesh repair versus double mesh intraperitoneal repair

Outcome: $\quad 05$ Deep venous thrombosis

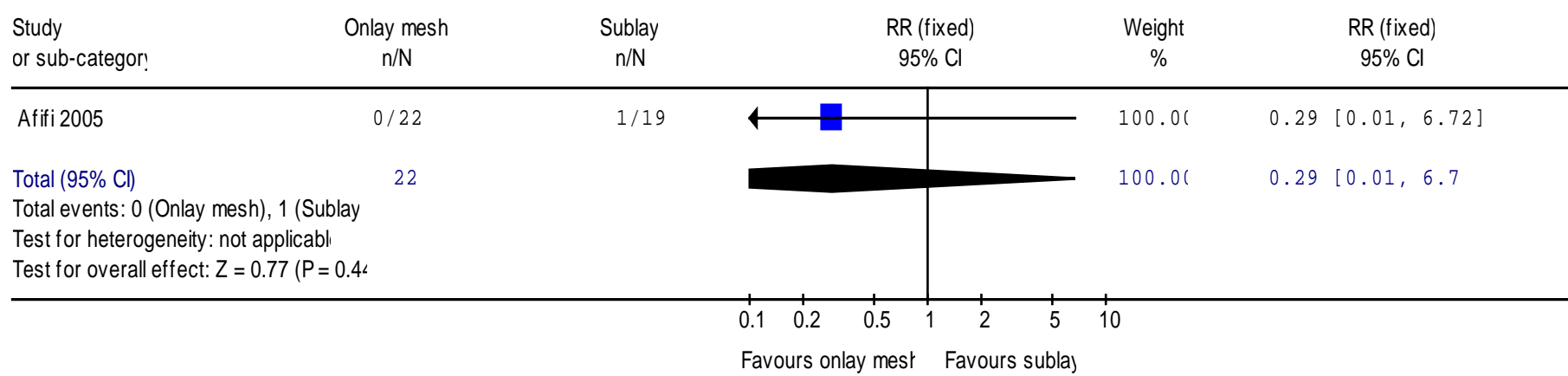


Review Open surgical procedures for incisional hernic

Comparison: 05 Onlay mesh repair versus double mesh intraperitoneal repair

Outcome: $\quad 06$ Fatal pulmonary embolism

\begin{tabular}{lcccc} 
Study & Onlay mesh & Sublay & RR (fixed) & Weight \\
or sub-categor! & $n / N$ & $n / N$ & $95 \% \mathrm{Cl}$ & $\%$ \\
\hline
\end{tabular}

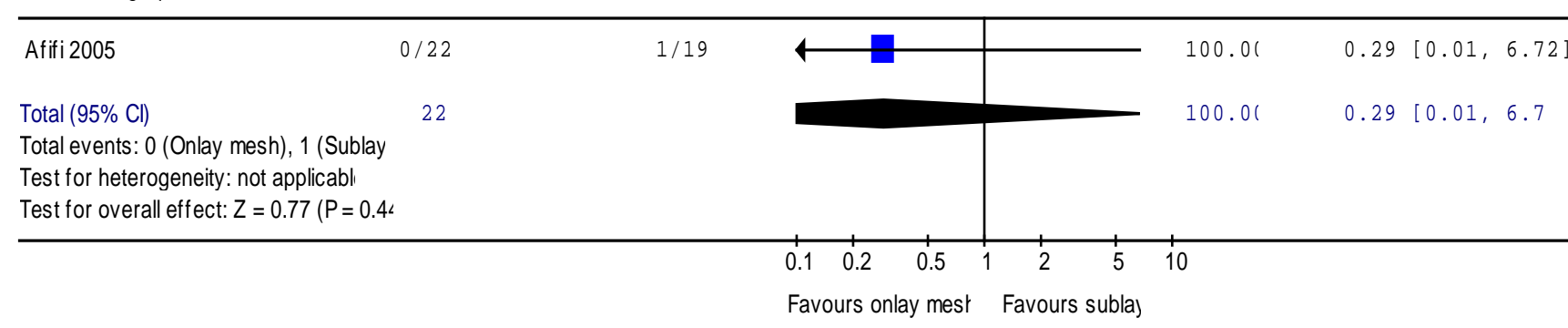

Review Open surgical procedures for incisional hernic

Comparison: 05 Onlay mesh repair versus double mesh intraperitoneal repair

Outcome: $\quad 07$ Postoperative pain ( $>6 \mathrm{mths}$ )

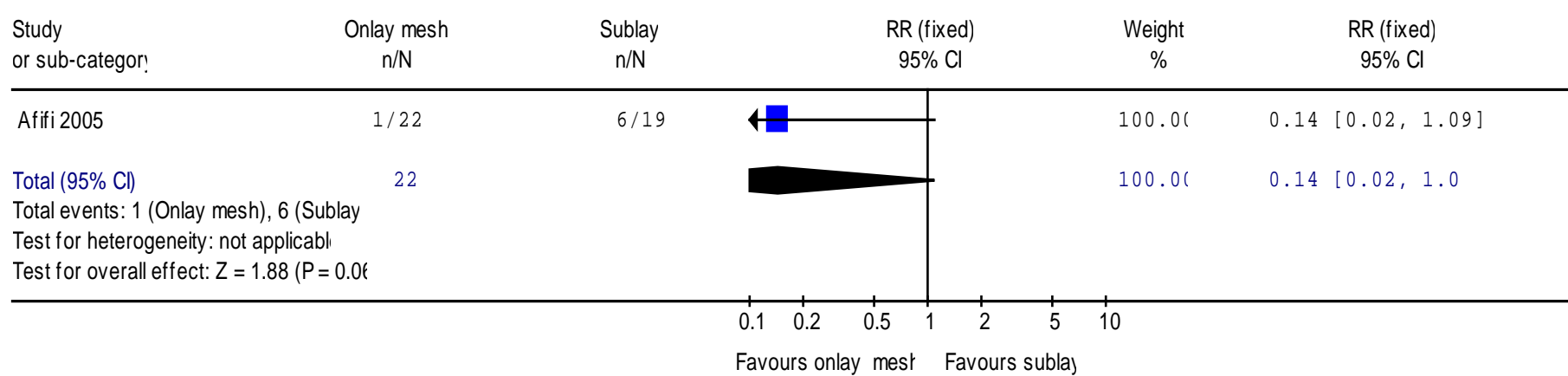

Review Open surgical procedures for incisional hernic

Comparison: $\quad 05$ Onlay mesh repair versus double mesh intraperitoneal repair

Outcome: $\quad 08$ Mesh removal

\begin{tabular}{|c|c|c|c|c|c|}
\hline Study & Onlay mesh & Sublay & RR (fixed) & Weight & RR (fixed) \\
\hline or sub-categor! & $\mathrm{n} / \mathrm{N}$ & $\mathrm{n} / \mathrm{N}$ & $95 \% \mathrm{Cl}$ & $\%$ & $95 \% \mathrm{Cl}$ \\
\hline
\end{tabular}

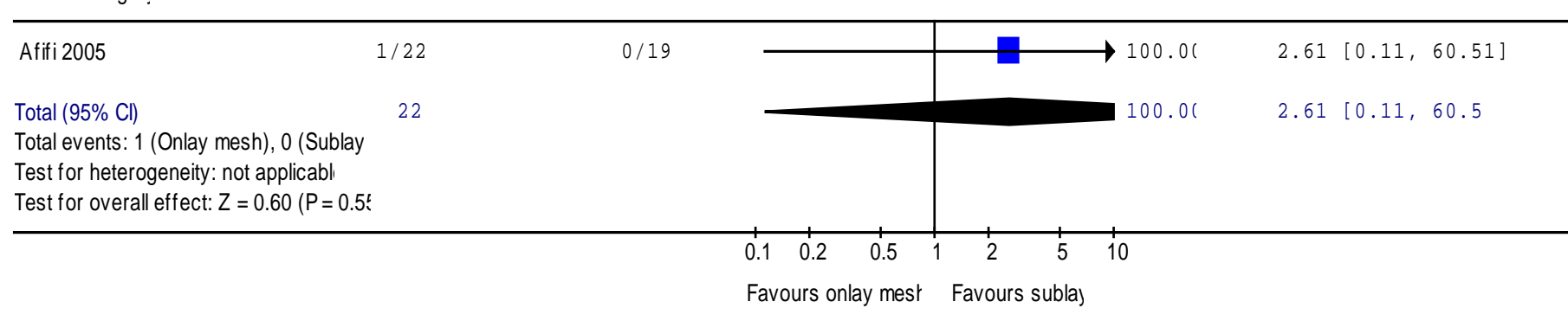


Review Open surgical procedures for incisional hernic

Comparison: 06 Components separation technique versus intraperitoneal prosthetic repair (giant hernias)

Outcome: 01 Recurrence

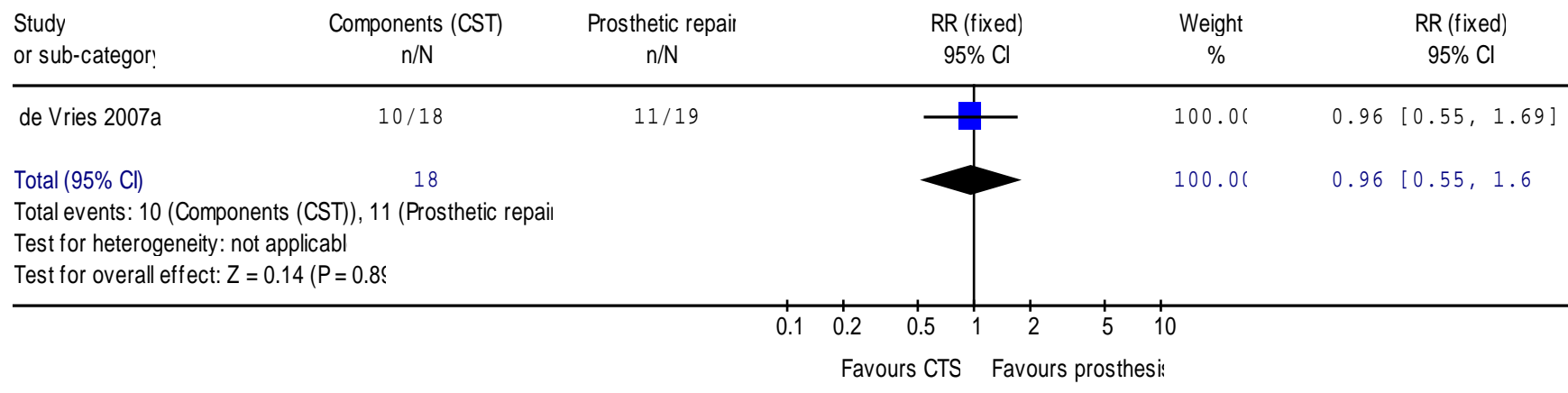

Review Open surgical procedures for incisional hernic

Comparison: 06 Components separation technique versus intraperitoneal prosthetic repair (giant hernias)

Outcome: $\quad 02$ Reoperation for w ound complications

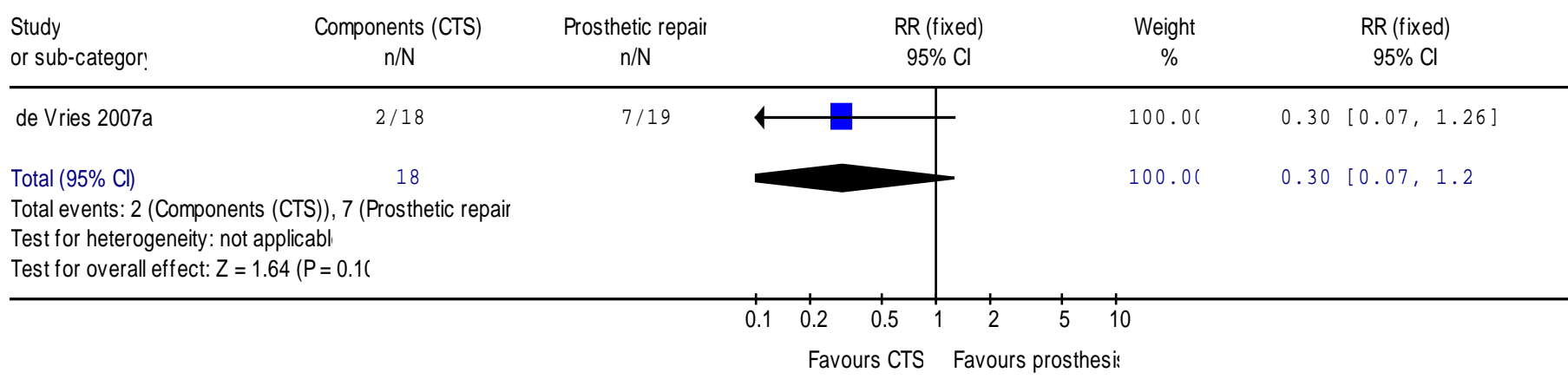

